\title{
Tendências da produção científica brasileira na área de Letras sobre letramento acadêmico na formação de professores
}

\author{
Elisa Bragança Curi Magalhães de Souza* \\ Jéssica do Nascimento Rodrigues**
}

\begin{abstract}
Resumo
Apesar de decorrer das práticas sociais vivenciadas pelos universitários, o ensino da escrita acadêmica tem sido pouco presente nos cursos de licenciaturas. Isso se reflete na formação desses estudantes e futuros professores, que costumam apresentar lacunas no ler-escrever textos da esfera acadêmica. Considerada ainda a escassez de produções científicas brasileiras acerca desse tema, este estudo busca investigar as principais tendências da produção científica sobre letramento acadêmico na formação de professores na área de Letras, publicadas no banco de teses da CAPES, entre 2013 e 2017, visando mapear os desafios e as contribuições do debate acerca do letramento acadêmico na formação de professores. Trata-se de uma pesquisa bibliográfica do tipo estado da arte que considera os trabalhos completos de dissertações e teses publicadas nessa plataforma e desenvolvidas no contexto brasileiro. Nessa investigação, encontraram-se apenas quatro trabalhos publicados sobre o tema na área de Letras, reafirmando a necessidade de investimento em pesquisa para avançar nas imbricações entre letramentos acadêmicos e letramento docente.
\end{abstract}

Palavras-chave: Letramento acadêmico. Letramento docente. Formação de professores. Estado da arte.

\footnotetext{
* Professora da educação básica em Niterói, Mestre em Psicologia Social (UNIVERSO) e graduada em Psicologia (FAMATh) e

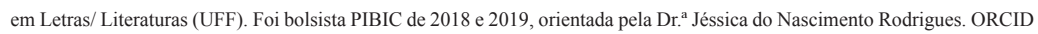
ID: https://orcid.org/0000-0002-4513-8519.

** Professora Adjunta da Faculdade de Educação da Universidade Federal Fluminense, líder do Grupo de Estudos e Pesquisa em Leitura e Escrita Acadêmica (GEPLEA) e coordenadora do Programa de Extensão Laboratório de Letramentos Acadêmicos (LabLA). ORCID ID: https://orcid.org/0000-0002-5859-0571.
} 


\title{
Trends in Brazilian Scientific Production in the Area of Letters on Academic Lettering in Teacher Training
}

\begin{abstract}
The teaching of academic writing in teacher training courses is still small, despite the social practices experienced by university students. This is reflected in the performance of these students and future teachers, who often present gaps in reading and writing academic texts and in academic research in the area of Literature, since there is a precariousness of Brazilian scientific productions. Therefore, this study seeks to investigate the main trends of scientific production on academic literacy in teacher education, published in the CAPES Thesis Bank, between 2013 and 2017, in order to map the challenges and contributions of the debate about academic literacy in the formation of teachers. This is a state-of-the-art bibliographic research that considers the complete works of theses and dissertations published in this platform and developed in the Brazilian context. In this investigation, only four published works on the subject in the area of Letters were found, reaffirming the need of investment in research to advance the imbrications between academic literacy and teaching literacy.
\end{abstract}

Keywords: Academic literacy. Teaching literacy. Teacher training. State of art.

Recebido em: 26/11/2019

Aceito em: 01/06/2020 


\section{Para iniciar o diálogo}

O ensino de língua materna, na escola básica, ainda se dá de modo compartimentado e fragmentado e destoa, cotidianamente, de sua real função ${ }^{1}$ e da interdisciplinaridade entre os outros saberes. O foco das aulas de língua materna no Ensino Médio, por exemplo, ainda tem sido a produção de um texto específico, dissertativo-argumentativo, que visa à aprovação para a entrada na universidade. Ao longo da educação básica, sobretudo, os alunos são massivamente levados a reproduzir conhecimentos de forma que, ao ingressarem no ensino superior, desconhecem práticas de produção e compartilhamento do conhecimento, materializadas em gêneros discursivos, diferentes daqueles que costumavam ler-escrever, assim como desconhecem eventos de letramento necessários para sua formação profissional. Tudo isso traz como consequência à vida acadêmica a dificuldade de ler e produzir gêneros acadêmicos, em sentido estrito, e de vivenciar a esfera acadêmica como interlocutor ativo e autônomo, em sentido lato. Dessa forma, no âmbito da universidade, muitos estudantes acabam por difundir a visão de que o ato de escrever é difícil, principalmente quando se deparam com textos teóricos que fazem uso de uma linguagem mais técnica, mais típica do campo do conhecimento, e distante daquele com o qual estavam habituados até então.

Essas questões podem ser sintetizadas nessa entrada do estudante no ensino superior, quando muitas transformações ocorrem na vida dos licenciandos, que logo percebem as

\footnotetext{
1 De acordo com Travaglia (2011), a função da educação linguística é o desenvolvimento da competência comunicativa a partir do "ensino/ aprendizagem, formais ou informais que levam uma pessoa a conhecer o maior número de recursos da sua língua e a ser capaz de usar tais recursos de maneira adequada para produzir textos a serem usados em situações específicas de interação comunicativa para produzir efeito(s) de sentido pretendido(s)" (TRAVAGLIA, 2011, p. 24).
} 
Tendências da produção científica brasileira na área de Letras sobre letramento acadêmico na formação de professores

aproximações e as diferenças entre a educação básica e o ensino superior, ainda que exista o discurso do letramento autônomo, como se o estudante não tivesse aprendido a ler e a escrever na escola e, por essa razão, sofra consequências no ler-escrever textos acadêmicos. Dentre as mudanças por eles vivenciadas, estão as especificidades dos eventos de letramento acadêmicos, a cobrança de uma postura adequada às práticas sociais a eles inerentes, a exigência de uma escrita mais monitorada, especializada, crítica e autoral e a produção oral e escrita de gêneros discursivos acadêmicos. Mais especificamente, os cursos de licenciatura, por vezes, tendem a não explorar e/ ou a incentivar a formação do docente pesquisador, de modo que esses futuros professores estejam preparados para lidar e relacionar seus conhecimentos teóricos com os práticos, numa interface, como práxis. Ao mesmo tempo, os professores, após concluírem sua graduação, costumam distanciar-se da academia, não imbricando o letramento acadêmico e o docente.

Com base nesses apontamentos, considera-se relevante trazer à baila o debate que coaduna letramentos acadêmicos e letramentos docentes. Para isso, este trabalho, fruto de pesquisa financiada pelo Programa Institucional de Bolsa de Iniciação Científica, da Universidade Federal Fluminense (PIBIC/ UFF), busca analisar e investigar as principais tendências da produção científica brasileira sobre letramento acadêmico na formação de professores, publicadas no banco de teses da CAPES e desenvolvidas sobre o contexto brasileiro no período de 2013 a 2017, na área de Letras. Caracterizado, portanto, como uma pesquisa bibliográfica do tipo estado da arte, seus objetivos específicos são: identificar as pesquisas no banco de teses da CAPES que abordem o tema do letramento acadêmico na 
formação docente; destacar as principais questões levantadas sobre a relação entre letramento acadêmico e formação de professores nos estudos mapeados; e analisar os referidos trabalhos, levantando os desafios e as contribuições do debate acerca do letramento acadêmico para a formação docente.

Vale acrescentar que este estudo busca refletir sobre a importância de uma formação docente sólida, no âmbito da academia, que se estenda às práticas situadas nas salas de aula da educação básica, sobretudo quando se sabe que os modos de ensinar-aprender mudam não apenas em decorrência das novidades teóricas promovidas pelas pesquisas universitárias, mas também pelas próprias práticas desenvolvidas nas escolas. Logo o letramento acadêmico e o docente são imprescindíveis e complementares, o primeiro se referindo às práticas de lerescrever situadas na universidade e o segundo, às práticas situadas na escola, as quais precisam colocar-se em intercâmbio, de modo que ambas caminhem no sentido das práticas de produção/ transformação/ reconstrução do conhecimento, colocando o professor das escolas públicas brasileiras no lugar de professor que pesquisa, que lê criticamente, que escreve, práticas essenciais à sua formação e às suas variadas formas de engajamento social.

\section{Letramentos acadêmicos e letramentos docentes em in- tercâmbio}

Entendendo que a linguagem é uma produção sóciohistórica e dialógica e ancorando-se no debate da Teoria da Enunciação, do Círculo de Bakhtin, e nos Estudos do Letramento, baseados na compreensão de que os letramentos são práticas 
sociais situadas em esferas discursivas, pode-se compreender que a academia apresenta práticas sociais letradas que desenham os gêneros discursivos próprios dessa esfera, que não isenta as relações hierárquicas e de poder. Acerca dessa temática, Bakhtin (2011) considera que

Todos os diversos campos da atividade humana
estão ligados ao uso da linguagem. Compreende-
se perfeitamente que o caráter e as formas desse uso
sejam tão multiformes quanto os campos da atividade
humana, o que, é claro, não contradiz a unidade
nacional de uma língua. O emprego da língua efetua-
se em forma de enunciados (orais e escritos) concretos
e únicos, proferidos pelos integrantes desse ou daquele
campo da atividade humana. (BAKHTIN, 2011, p. 261,
grifo nosso).

A partir disso, deve-se reconhecer que, a todo tempo, os usuários de uma determinada língua fazem uso dela no mundo, para o mundo, com o mundo e com os outros. Ademais, esses enunciados mostram as condições e os objetivos de cada campo da atividade humana, elaborando seus tipos relativamente estáveis, como denomina o autor, ou seja, os gêneros discursivos.

Na esfera acadêmica, de acordo com Lea e Street (1998), é possível pensar o letramento como um conjunto de habilidades individuais e cognitivas que os alunos devem aprender e, assim, desenvolver, a fim de transferi-las para os contextos mais amplos da universidade. Além disso, para Street (2014), o letramento não pode ser considerado como autônomo, haja vista que práticas particulares e concepções de uso da escrita dependem do contexto ideológico bem como os usos da escrita, que não podem ser tratados como neutros ou universais, visto que são socialmente determinados. Dessa forma, eles têm, então, valores e significados específicos para cada comunidade 
e contexto. Nessa mesma perspectiva, os Estudos de Letramento (EL) concebem esse conceito como práticas de uso da escrita consideradas "práticas sociais plurais e heterogêneas, vinculadas às estruturas de poder das sociedades" (VIANNA et al., 2016, p. 28). Isto é, tal visão considera os letramentos acadêmicos como um conjunto de habilidades de leitura e escrita aprendidas em situação de formação profissional superior, vinculando-os aos diversos valores atribuídos às práticas de ler-escrever pelos sujeitos. Também é necessário considerar que essa prática social ainda é marcada pelas relações de poder que variam conforme os contextos de uso da língua. Os letramentos acadêmicos, portanto, ocorrem por meio de práticas que orientam a vida na universidade, incluindo "a produção ou a recepção de gêneros acadêmicos de prestígio que variam de acordo com os campos disciplinares" (BEZERRA, 2015, p. 62).

Ao pensar na dimensão formadora dos letramentos acadêmicos voltados para o letramento docente, cabe refletir, especialmente, no que tange a área de Letras, objeto de análise deste estudo, a escassez de pesquisas que tratem sobre esses dois aspectos de modo mais aprofundado. Ferreira e Lousada (2016) acreditam que, no Brasil, o ensino da escrita acadêmica é quase inexistente. As autoras ainda sugerem que tal aprendizado poderia ser mais presente na graduação de Letras, com cursos de produção textual, leitura ou ainda de metodologia científica, no entanto o que se encontra é um ensino isolado da habilidade escrita, que traz como consequência a desvinculação das disciplinas do currículo.

Desse modo, a implicação dos saberes docentes acadêmicos na formação docente mostra-se primordial para que os futuros profissionais tenham conhecimento teórico e prático e, assim, 
possam produzir conhecimento, sentindo-se pertencentes aos diferentes campos do saber, sejam acadêmicos, sejam docentes, sejam, portanto, acadêmico-docentes. Sobre isso, Valsechi e Pereira (2016, p. 437) compreendem que:

Para que a universidade esteja voltada à função a ela atribuída de formação do profissional docente, a nosso ver, é preciso romper com a tradicional postura que toma os saberes academicos como ponto de partida ou chegada [...], e buscar formas de proporcionar a (re) construção de conhecimentos docentes a partir das suas demandas profissionais, na articulação entre saberes e práticas de ambas as esferas (acadêmica e profissional). (VALSECHI; PEREIRA, 2016, p. 437, grifo nosso)

Para as autoras, as instituições de ensino superior passam a ter papel fundamental nessa apropriação de saberes e, por isso, devem vislumbrar uma posição mais ativa no que tange à construção de conhecimentos diversos, partindo das necessidades profissionais e na articulação entre teoria e prática. $\mathrm{O}$ que se vem observando, contudo, é um distanciamento desses espaços, tidos como práticas dissociadas, seja no âmbito acadêmico, seja no escolar: como se no primeiro, o conhecimento fosse produzido e, no segundo, reproduzido/ compartilhado.

Lea e Street (1998, 2014) e Russell (2009) comentam que essas dificuldades são encontradas e vivenciadas pelos estudantes porque as convenções que regem a esfera acadêmica são distintas daquelas que orientam a educação básica, ou seja, há maneiras de agir e interagir, entre outros aspectos, que são específicos a cada espaço. No que tange especificamente aos cursos de licenciaturas, tal problemática se torna ainda mais preocupante, pois a prática do ensino e da pesquisa é constitutiva do cenário docente. Nesse sentido, Souza e Bassetto (2014) enfatizam que o conhecimento dos gêneros discursivos acadêmicos, quanto 
às suas características estruturais, discursivas, pragmáticas e retóricas, é um dos meios que instrumentalizam os aprendizes para a prática da pesquisa, reflexão crítica e formação como professores-pesquisadores.

\section{Caminhos teórico-metodológicos}

Entendendo que os letramentos acadêmicos e os docentes ocorrem em intercâmbio, faz-se imprescindível a reflexão acerca da importância de uma formação docente no ensino superior que contribua com o desenvolvimento da autonomia docente no ler-escrever textos acadêmicos e, ainda, no ensino dos textos na escola, já que atuarão nos letramentos de outros sujeitos. É importante enfatizar que os letramentos acadêmicos ocorrem por meio das práticas de ler-escrever na universidade, enquanto o letramento docente vincula-se às práticas situadas na escola, as quais precisam colocar-se em comunicação, de modo que ambas caminhem no sentido das práticas de produção/ transformação do conhecimento, colocando o professor da educação básica no papel de professor que pesquisa, que lê criticamente, que escreve, práticas essenciais à sua formação e às suas variadas formas de engajamento social.

Dessa forma, esse estudo objetivou fazer um levantamento das principais tendências da produção científica brasileira sobre letramento acadêmico na formação de professores. Para tanto, a metodologia escolhida foi a análise bibliográfica do tipo estado da arte, cujo desafio foi o de mapear e discutir a produção acadêmica na área de Letras. Para isso, elencaram-se alguns procedimentos, tendo como base o banco de teses da CAPES, importante espaço de discussões acerca dos rumos da pesquisa 
Tendências da produção científica brasileira na área de Letras sobre letramento acadêmico na formação de professores

em educação no País, no contexto brasileiro do período de 2013 a 2017. Logo foram encontrados quatro trabalhos, sendo uma tese e três dissertações que evidenciam a relação entre letramentos acadêmicos e docentes.

Em síntese, o estado da arte, metodologia utilizada nesta pesquisa, trata de uma revisão bibliográfica acerca de um tema específico em uma dada área do conhecimento. Segundo Silva e Carvalho (2014), deve-se considerar o tempo e o espaço para a realização de um estado da arte. De acordo com as autoras, "o recorte temporal e espacial nesse método é necessário porque as análises feitas referem-se a concepções e práticas presentes em determinados contextos sociais, políticos, econômicos, culturais etc." (SILVA; CARVALHO, 2014, p. 349). Além disso, o recorte temático delimita o mapeamento proposto para estudos mais ou menos aprofundados.

Tomou-se, portanto, como material de consulta, as palavraschave e os resumos das teses e dissertações publicadas no banco da CAPES e posterior análise qualitativo-interpretativista de algumas dessas teses na íntegra, após seleção de uma amostra intencional. Compreendem-se, para isso, os estudos realizados sobre o contexto brasileiro no período de 2013 a 2017, os quais versem especificamente sobre o letramento acadêmico na formação docente. Reconhece-se, nesse sentido, que o letramento acadêmico, como uma nova tendência dos estudos na área da educação em articulação com as teorias da linguagem, imbrica-se ao letramento do professor que atuará nas salas de aula da educação básica: do ensino regular à Educação de Jovens e Adultos (EJA). Optou-se pelo banco de teses da CAPES em virtude de sua importância como "relevância do banco de dados em tela como fonte de pesquisa, especialmente pelo seu 
caráter multidisciplinar e pela sua vasta abrangência, uma vez que abarca trabalhos de IES públicas e particulares de todo o território nacional e das mais diferentes áreas do conhecimento" (VIEIRA; MACIEL, 2007, p. 366).

Em vista disso, os trabalhos selecionados para análise e reflexão desta pesquisa são os seguintes: Letramentos acadêmicos: práticas e eventos de letramento na educação a distância, de Amanda Cavalcante de Oliveira Lêdo (UFPE); Letramentos acadêmicos em um curso de letras/inglês: o discurso do projeto político pedagógico e o discurso de alunos e egressos, de Betyna Faccin Preischardt (UFSM); Relocalização de saberes acadêmicos na construção de vozes de professores em formação inicial na escrita acadêmica convencional e reflexiva, de Bruno Gomes Pereira (UFT); e Letramentos acadêmicos de alunos de Letras de uma universidade do Sul do Brasil, de Fernanda Lopes Silva Ziegler (UFSM). As discussões e considerações sobre os levantamentos acerca dessas pesquisas serão abordados a seguir.

\section{Letramentos acadêmicos e letramentos docentes: um de- bate incipiente}

À procura de uma amostra intencional para análise da temática em questão, observou-se a baixa frequência de estudos sobre o tema, chegando ao número de quatro teses e dissertações, das quais três são dissertações e uma, tese. Foi possível fazer uma análise dos referidos trabalhos, levantando alguns desafios e contribuições para este debate. $\mathrm{Na}$ intenção de mapear os temas recorrentes e os pontos de convergência, pode-se observar que essas pesquisas visam entender o modo como os letramentos 
Tendências da produção científica brasileira na área de Letras sobre letramento acadêmico na formação de professores

acadêmicos se realizam, bem como quais gêneros textuais estão presentes na jornada acadêmica dos estudantes. Além disso, é perceptível a preocupação existente com as relações de poder e o modo como esses gêneros acadêmicos são apresentados aos discentes. A seguir, são apresentadas as pesquisas e suas contribuições para esse debate.

A dissertação intitulada Letramentos acadêmicos: práticas e eventos de letramento na educação a distância, com autoria de Amanda Cavalcante de Oliveira Lêdo, defendida em 2013, na Universidade Federal de Pernambuco (UFPE), teve como problemática de estudo a investigação sobre as nuances das práticas realizadas no contexto a distância, visto que cada vez mais essa modalidade vem se desenvolvendo e formando uma gama de profissionais das mais diversas áreas.

O trabalho teve como objetivo geral investigar, considerando o conceito de gênero textual, quais são e como se apresentam as práticas e os eventos de letramento que acontecem no Ambiente Virtual de Aprendizagem (AVA) de um curso de graduação em Letras a distância bem como as percepções/juízos de valor que os participantes da interação, professores e alunos, constroem acerca desses eventos. Mais especificamente, objetivou identificar o conjunto de gêneros com o qual os alunos lidam (produtiva e receptivamente) ao estarem inseridos no sistema de atividades da universidade; descrever as práticas e os eventos de letramento que ocorrem nas disciplinas do curso de Letras a distância, analisando como os gêneros aparecem no AVA, por quem e como são usados durante o semestre letivo; analisar a percepção, as crenças e os valores dos participantes da interação (alunos e professores) durante o processo de ensino-aprendizagem acerca dos gêneros principais presentes nos eventos de letramento que 
ocorrem nas disciplinas.

A abordagem teórica escolhida pela autora foi Estudos do Letramento, buscando como principais autores Lea e Street (1998), Barton e Hamilton (2005) e Street (2007, 2010, 2012). A metodologia utilizada para atingir os objetivos desse trabalho foi: aplicação de questionário com cinco alunos do polo de Garanhuns, os quais se disponibilizaram a responder; realização de entrevistas presenciais com professores e alunos do curso de graduação em Letras a distância; e acompanhamento das disciplinas pela pesquisadora através da observação do AVA. A abordagem foi de cunho etnográfico.

As principais considerações desse trabalho versaram sobre a compreensão de que, em um curso de graduação a distância, embora as práticas de letramento sejam em grande parte idênticas às que se verificam no ensino presencial, cada modalidade ocorrida em diferentes contextos se organiza a partir de eventos de letramento específicos, diferentes de outros ambientes educacionais, mediados por gêneros típicos do processo de ensino-aprendizagem ocorridos no Ambiente Virtual de Aprendizagem, como o fórum e a WebQuest, os quais, apesar de se realizarem em outros contextos, na $\mathrm{EaD}$ adquirem um papel quase central. O AVA se configura como um espaço no qual ocorrem variados eventos de letramento e, dessa forma, os gêneros incorporam as características salientes no ambiente eletrônico, como a prevalência de gêneros escritos, em detrimento dos orais, e a organização hipertextual e multimodal mais evidente do que em outros suportes. Para o estudo, isso não significa que, no ensino presencial, o estudante não necessite desenvolver o letramento digital, entretanto o letramento acadêmico pressupõe o conhecimento sobre tecnologia. A 
Tendências da produção científica brasileira na área de Letras sobre letramento acadêmico na formação de professores

pesquisadora acredita que deva ocorrer um contínuo entre as duas modalidades, em que no ensino presencial tenha-se alguma atividade em meio virtual, a exemplo de projetos que utilizam blogs e redes sociais diversas para explorar as experiências pedagógicas on-line, e que no ensino a distância aconteçam encontros presenciais nos respectivos polos, como eventos para obtenção de certificados de participação em atividades acadêmicas diversas ou participação em videoconferência, por exemplo. Ainda que de forma iniciante, o estudo entende que a forma como os gêneros são apresentados aos estudantes aponta para uma concepção voltada para a abordagem dos letramentos acadêmicos (LEA; STREET, 1998), no sentido de que, além de buscar englobar a socialização do aluno dentro dos gêneros e das práticas da comunidade acadêmica, a partir das orientações mais ou menos explícitas oferecidas pelos professores, os docentes demonstram a preocupação com o engajamento dos estudantes no desenvolvimento da criticidade e da consciência da importância de conhecer os gêneros típicos da academia para sua formação acadêmica e profissional.

A dissertação Letramentos acadêmicos em um curso de Letras/Inglês: o discurso do projeto político pedagógico e o discurso de alunos e egressos, de Betyna Faccin Preischardt, defendida em 2015, na Universidade Federal de Santa Maria (UFSM), teve como problemática de estudo a análise do discurso político institucional, assim como do discurso dos participantes do Curso de Letras/ Inglês (CLI) em relação aos letramentos acadêmicos - com ênfase nas práticas de produção textual escrita. Seu objetivo geral foi analisar criticamente o discurso do Projeto Político Pedagógico (PPP) e de alunos e egressos de um curso de Letras/Inglês sobre as práticas e os eventos de letramentos 
acadêmicos na formação como profissional de línguas em uma universidade federal do sul do Brasil, no centro do Rio Grande do Sul.

Os objetivos específicos foram: identificar e discutir as práticas e eventos de letramentos acadêmicos previstas no PPP ao longo do referido curso; identificar, no discurso de alunos e de egressos, as práticas e os eventos de letramentos acadêmicos vivenciados e experienciados por eles concretamente durante o CLI; discutir a relação entre práticas e eventos de letramentos acadêmicos previstos no PPP e implementados, conforme identificados no discurso de alunos e egressos.

O trabalho escolheu como abordagem teórica a Análise Crítica de Gênero (ACG), com os autores Meurer (2002), Motta-Roth (2005) e Motta-Roth e Scherer (2012); a Análise Crítica do Discurso, com Fairclough (1992, 1995, 2003); a Sociorretórica, com Miller (1984) e Swales (1990) e Bazerman (2005); e a Gramática Sistêmico-Funcional, com Halliday e Matthiessen (2004). A metodologia escolhida foi a etnografia da comunicação, aplicada com estudantes do Curso de Licenciatura em Letras/ Inglês, no período de agosto de 2014 a setembro de 2015. Para obter as informações sobre as práticas e atividades sociais da comunidade estudada, escolheu-se analisar o PPP e aplicar questionários com os alunos e egressos do curso de graduação, a fim de complementar e refinar as informações levantadas pela análise do PPP.

Essa dissertação pretendeu contribuir com reflexões e informações acerca dos processos de ensino e aprendizagem dentro do contexto do CLI, a partir do reconhecimento das práticas e dos eventos de letramentos acadêmicos previstas/os no PPP e implementadas/os pelo discurso dos alunos e egressos. 
Tendências da produção científica brasileira na área de Letras sobre letramento acadêmico na formação de professores

Com esses dois enfoques, o objetivo do trabalho foi discutir as relações entre os discursos acerca do que é previsto e o que é vivido, em relação aos letramentos acadêmicos, especificamente a prática de produção textual escrita e como o desenvolvimento dos letramentos acadêmicos torna-se importante para a formação de alunos e egressos como professores de língua inglesa. Foi possível reconhecer, tanto no discurso do PPP quanto no dos alunos e egressos, três práticas de letramentos acadêmicos que evidenciam o diálogo entre si, de modo que uma parece constituir a outra, previstas para os estudantes do CLI: participação em projetos; produção e consumo de textos; e atuação profissional. Para a pesquisa, isso significa que o entrelaçamento das práticas só acontece entre produção e consumo de textos com participação em projetos e produção e consumo de textos com atuação profissional. Evidenciou-se, nesse estudo, também a importância do papel do professor formador como mediador do conhecimento e promotor de diferentes práticas de produção textual escrita durante as disciplinas e projetos a fim de compreender os textos como processos e produtos constitutivos (HALLIDAY; HASAN, 1985) dessas atividades. A relevância desse trabalho se apresenta ao conseguir construir diálogos em relação às representações das práticas e dos eventos de letramentos acadêmicos, dos papéis desempenhados e das identidades constituídas pelos estudantes e egressos, nos discursos do PPP e de alunos e egressos.

A tese Relocalização de saberes acadêmicos na construção de vozes de professores em formação inicial na escrita acadêmica convencional e reflexiva, de Bruno Gomes Pereira, defendida em 2016, na Universidade Federal do Tocantins (UFT), questiona: como a relocalização de saberes acadêmicos contribui na construção de vozes de professores em 
formação inicial, gerando condições favoráveis para tentativas de criação de objetos de ensino? O conceito de relocalização, nessa pesquisa, é baseado nos estudos de Pennycook (2010), que considera a língua como prática social e entende a relocalização como esforço para se distanciar do que seria uma mera repetição do discurso, que, uma vez readequado às condições contextuais, gera novos sentidos. Sendo assim, trata-se de uma remodelação criativa da linguagem.

Tal estudo teve como objetivo geral analisar o modo como a relocalização de saberes acadêmicos, enquanto recurso semântico na materialidade textual, contribui para a construção de vozes sociais de professores em formação inicial, aqui denominados de alunos-mestre, a partir da escrita acadêmica convencional e da reflexiva profissional. E como objetivos específicos, apresenta: compreender as Resenhas Acadêmicas (RA) e os Relatórios de Estágio Supervisionado (RES) como gêneros acadêmicos capazes de propiciar a articulação de saberes acadêmicos com a prática pedagógica no contexto da formação inicial do professor; caracterizar configurações de vozes dos professores em formação inicial construídas nas RA e nos RES, utilizando as metafunções da linguagem descritas como categorias analíticas na Linguística Sistêmico-Funcional (LSF). Também pretendeu comparar os resultados produzidos a partir dos objetivos específicos, compreendendo como essas ocorrências gramaticais caracterizam a tomada de vozes de alunos-mestre a partir da teoria por eles mobilizada; caracterizar, por fim, marcas linguísticas específicas da mobilização de saberes acadêmicos na tentativa de construção de objetos de ensino.

Teve como abordagem teórica a Linguística Aplicada Interdisciplinar, a partir de Moita Lopes (2013, 2006). Mey 
Tendências da produção científica brasileira na área de Letras sobre letramento acadêmico na formação de professores

(2014, 2001, 1998), Bakhtin (1984), Thompson (2014), Fiad (2011), Motta-Roth (2013, 2011), Motta-Roth e Hendges (2010), Moyano (2013) e Signorini (2006) também foram autores importantes para esse estudo, mesclando a concepção bakhtiniana de linguagem aos Estudos do Letramento. A metodologia escolhida teve como corpus 10 (dez) RA e 20 (vinte) RES produzidos por alunos-mestre de Licenciatura em Letras, Língua Portuguesa, ofertada pela Universidade Federal do Tocantins (UFT), campus Araguaína. A abordagem de análise dos dados foi a qualitativo-interpretativista.

Ao longo desse estudo, foi desenvolvido um percurso de análise referente à construção de diferentes vozes sociais de alunos-mestre de uma Licenciatura em Letras (Língua Portuguesa), a partir da relocalização de saberes acadêmicos, com vistas à tentativa de construção de objetos de ensino em RA e RES, os quais se realizam por meio da escrita acadêmica convencional e da reflexiva profissional, respectivamente. As análises revelaram que as construções das vozes de professores em formação inicial, considerando as relações de poder estabelecidas entre atores sociais da escola básica e da universidade, permeiam o contexto da sala de aula. Também foi possível observar a construção do próprio perfil do alunomestre marcado por construções identitárias que nos ajudam a compreender a disparidade entre escola e universidade. Além disso, ilustra a tensão provocada pelo empoderamento do aluno-mestre e a marginalização do PEB, ou vice-versa, o que depende do olhar sistemático de diferentes pesquisadores a respeito do corpus analisado. Logo o desenvolvimento das potencialidades de letramento no contexto universitário, a partir do melhoramento no manuseio da escrita acadêmica, constrói 
a ideia de relocalização de saberes acadêmicos materializados por meio da troca de posição dos atores sociais envolvidos. Os saberes acadêmicos, na licenciatura referida, não são lineares, ao se considerar a matriz curricular do curso. Isso é marcado pela falta de conexão entre a ideia de prática de ensino e as disciplinas ditas teóricas. Diante disso, a relação entre prática e teoria tornase possível apenas a partir da percepção do professor formador que ministra a disciplina de perfil puramente teórico.

\section{Letramentos acadêmicos de alunos de Letras de uma} universidade do Sul do Brasil é uma dissertação escrita por Fernanda Lopes Silva Ziegler, defendida em 2015, na Universidade Federal de Santa Maria. Objetivou analisar o discurso de alunos de Letras e do Laboratório de Linguística Aplicada (LLAp), que se baseia no tripé ensino, pesquisa e extensão, sobre suas práticas discursivas acadêmicas, de modo a identificar as características dos processos de letramentos acadêmicos que contribuem para a aprendizagem dos estudantes. Mais específicos, os objetivos foram norteados pelas seguintes perguntas: o curso de Letras e o LLAp configuram uma comunidade de prática conforme o conceito adotado neste estudo?; Quais são os discursos dos alunos de Letras sobre letramentos e quais são, segundo eles, os eventos e as práticas sociais de letramentos nos processos de construção do conhecimento?; Em que medida os dados reforçam ou refutam o argumento de que as habilidades, as competências e as condições discursivas, envolvidas no[s] letramento[s] acadêmico[s], dependem de uma aprendizagem mediada pela participação periférica legítima $(\mathrm{PPL})^{2}$ em uma comunidade estruturada para receber novos

\footnotetext{
2 Participação Periférica Legítima (PPL) é um conceito de Lave e Wenger (1991) que pode ser compreendido como um processo gradual de inserção, colaboração e engajamento dos sujeitos na aprendizagem dos letramentos acadêmicos, estando relacionada à posição do sujeito no mundo social com vistas ao desenvolvimento de sua própria identidade.
} 
membros, dar-lhes acesso crescente e, desse modo, formá-los para participar integralmente na comunidade como membros expertos (MOTTA-ROTH, 2013a, p. 10)? A abordagem teórica sobre letramentos acadêmicos que direciona essa pesquisa foi: Linguística Aplicada/Análise Crítica do Discurso (ACD), com base nos autores Fairclough (1992) e Meurer (1993); Estudos do Letramento, com Lea e Street (1998) e Barton (2010); Teoria da Enunciação, com Bakhtin (1992); e Análise Crítica de Gênero (ACG), com Motta-Roth (2010). Para atingir o objetivo geral deste estudo, a ACD viabilizou o desenvolvimento de uma análise que visa à descrição, interpretação e explicação das características dos letramentos acadêmicos.

Como método, adotou a perspectiva etnográfica, que leva em conta a necessidade de considerar a visão dos participantes sobre o contexto social que se deseja estudar. Para alcançar os resultados desejados, foram aplicados questionários semiestruturados sobre temas referentes às práticas e aos eventos de letramentos acadêmicos nas comunidades e entrevistas semiestruturadas feitas a partir das respostas dadas nos questionários. No total, o questionário foi entregue, aplicado e/ou enviado a aproximadamente 94 discentes dos cursos de Licenciatura em Letras/ Inglês, Letras/ Espanhol e Pós-Graduação em Letras/ Estudos Linguísticos.

As principais considerações levantadas por essa pesquisa foram a de que alunos de Letras desenvolvem letramentos acadêmicos quando produzem gêneros para fins específicos e desempenham papéis sociais no contexto onde estão inseridos os gêneros mais rotineiros e formulaicos, tais como as "resenhas", os "resumos" e os "artigos". De acordo com o estudo, os alunos parecem desenvolver letramentos acadêmicos na área 
do saber de Letras em duas práticas sociais principais. Uma, quando produzem gêneros para fins específicos, como para participação em eventos e divulgação dos resultados de pesquisa, especialmente em coautoria, e outra, quando desempenham papéis sociais, por exemplo, como tutores em cursos de línguas e IC em projetos de pesquisa, o que ocorre, especialmente, entre os participantes do LLAp. Segundo a experiência da pesquisadora,

[...] a inserção e participação no laboratório, desde o primeiro semestre da graduação em Letras, o engajamento em diferentes práticas de letramentos acadêmicos no tripé ensino, pesquisa e extensão, ao longo de aproximadamente seis anos, contribuíram para a produção textual escrita desta dissertação e para o aprendizado diário das práticas sociais vivenciadas e das relações sociais estabelecidas no LLAp. (ZIEGLER, 2015, p. 121).

Tendo em vista os quatro estudos escolhidos, é possível perceber algumas aproximações e certos distanciamentos no que toca aos objetivos, às abordagens teóricas, às metodologias e, finalmente, aos resultados. No que se refere aos temas, todos se mostram inovadores e relevantes ao debate em questão, já que tratam de modos diversos a problemática dos letramentos acadêmicos na formação docente.

Isso se observa na seleção das questões propostas em cada pesquisa, que abrange, por exemplo, a relação do letramento acadêmico com o digital, evidenciando a necessidade de um contínuo entre essas modalidades, deixando clara a importância de se analisarem as práticas e os eventos de letramento no contexto a distância, bem como compreendendo o modo como ocorrem.

Além disso, discutir as práticas e os eventos de letramento previstos no Projeto Político Pedagógico e como são realmente 
implementados conforme o discurso de alunos e egressos dialoga com a pesquisa selecionada de Pereira (2016), que visa analisar o percurso de construção de diferentes vozes sociais dos alunos, entendendo a escrita acadêmica convencional e reflexiva profissional. Com isso, mostra-se a importância de valorizar o desenvolvimento de potencialidades de letramento acadêmico.

Sendo assim, os trabalhos consideram a necessidade de construção de diálogos na formação profissional, enfatizando a importância do papel do professor como produtor do conhecimento, como um dos papéis sociais que assume na docência enquanto práxis.

\section{Considerações finais}

Tendo em vista a discussão em debate, mostra-se relevante a reflexão sobre a importância dos letramentos acadêmicos na formação de professores, como parte fundamental do desenvolvimento profissional. Com isso, pesquisar os principais temas e questionamentos relativos à caminhada acadêmica nos cursos de licenciatura, no que se refere às práticas sociais letradas, é fundamental para a ampliação do conhecimento nessa área, assim como para colocar em cena o debate acerca desses letramentos: os acadêmicos e os docentes.

As principais questões levantadas sobre a relação entre letramento acadêmico e letramento docente estão voltadas para a compreensão das relações entre práticas de letramento com a formação de identidades docentes. Assim, segundo as dissertações e a tese aqui analisadas, as disciplinas cursadas na universidade mostram sua relevância ao possibilitar a contribuição de construção dos saberes docentes adquiridos por 
meio das práticas diversificadas de letramento. Tal tese apoiase, então, na perspectiva de que a formação inicial possibilita aos professores a vivência de múltiplos letramentos, no sentido de formá-los como sujeitos letrados, letradores e sempre em processo de formação.

Todas essas observações confirmam que a discussão acerca do letramento acadêmico ainda é recente e pouco valorizada como parte essencial da formação profissional, em busca da interlocução com a prática docente. Além disso, cabe acrescentar que o professor universitário tem papel fundamental na formação acadêmica dos licenciandos, visto que lhe cabe a mediação, a orientação e a promoção de diferentes práticas e eventos de letramento situados nas esferas acadêmica e docente, de modo que os estudantes se sintam pertencentes a esse ambiente e possam retornar a ele, quando já formados, produzindo e compartilhando, dialética e dialogicamente, no coletivo, o conhecimento.

\section{Referências}

BAKHTIN, M. Estética da criação verbal. 2. ed. São Paulo: Martins Fontes, 2011

BEZERRA, B. Letramentos acadêmicos e construção da identidade: a produção do artigo científico por alunos de graduação. Linguagem em (Dis)curso, v. 15, n. 1, p. 61-76, 2015.

FERREIRA, M. M.; LOUSADA, E. G. Ações do Laboratório de Letramento Acadêmico da Universidade de São Paulo: promovendo a escrita acadêmica na graduação e na pósgraduação. Ilha Desterro [online], v. 69, n. 3, p. 125-140, 2016. 
Tendências da produção científica brasileira na área de Letras sobre letramento acadêmico na formação de professores

LEA, M. R.; STREET, B. V. Student writing in higher education: An academic literacies approach. Studies in Higher Education, Abingdon, Oxon, UK, v. 23, n. 2, 1998.

LÊDO, A. C de O. Letramentos acadêmicos: práticas e eventos de letramento na educação a distância. 2013. Dissertação (Mestrado em Linguística) - Centro de Artes e Comunicação, Universidade Federal de Pernambuco, Recife, 2013.

PEREIRA. B. G. Relocalização de saberes acadêmicos na construção de vozes de professores em formação inicial na escrita acadêmica convencional e reflexiva. 2016. Tese (Doutorado em Letras) - Programa de Pós-Graduação em Letras: Ensino de Língua e Literatura, Universidade Federal do Tocantins, Araguaína, 2016.

PREISCHARDT, B. F. Letramentos acadêmicos em um curso de letras/inglês: o discurso do projeto político pedagógico e o discurso de alunos e egressos. 2015. Dissertação (Mestrado em Letras) - Centro de Artes e Letras, Universidade Federal de Santa Maria, Santa Maria, 2015.

RUSSELL, D. et al. Exploring notions of genre in "Academic Literacies" and "Writing across the Curriculum": approaches across countries and contexts. In: Bazerman, Charles; Bonini, Adair and Figueiredo, Débora eds. Genre in a Changing World: perspectives on Writing. Colorado: WAC Clearinghouse/Parlor Press, 2009. p. 459-491.

SILVA, F. J. da C.; CARVALHO, M. E. P. de. O estado da arte de pesquisas educacionais sobre gênero e educação infantil: uma introdução. In: REDE FEMINISTA NORTE E NORDESTE DE ESTUDOS E PESQUISA SOBRE A MULHER E RELAÇÕES GÊNERO: perspectivas feministas de gênero: desafios no campo da militância e das práticas, 18, 2014. Recife. Anais... Universidade Federal Rural de Pernambuco, Recife, 2014.

SOUZA, M. G. de; BASSETTO, L. M. T. Os processos de apropriação de gêneros acadêmicos (escritos) por graduandos em 
letras e as possíveis implicações para a formação de professores/ pesquisadores. Revista Brasileira de Linguística Aplicada, Belo Horizonte, v. 14, n. 1, p. 83-110, 2014.

VALSECHI, M. C.; PEREIRA, S. L. M. (Des)caminhos para o letramento do professor no espaço da formação docente. In: KLEIMAN, Angela B.; ASSIS, Juliana Alves. (org.). Significados e ressignificações do letramento: desdobramentos de uma perspectiva sociocultural sobre a escrita. Campinas, SP: Mercado de Letras, 2016. p. 411-440.

VIANNA, C.A. D.; SITO, L.; VALSECHI M. C.; PEREIRA, S. L. M. Do letramento aos letramentos: desafios na aproximação entre letramento acadêmico e letramento do professor. In: KLEIMAN, A. B.; ASSIS, J. A. (org.). Significados e Ressignificações do Letramento: desdobramentos de uma perspectiva sociocultural sobre a escrita. Campinas, SP: Mercado de Letras, 2016. p. 2759.

VIEIRA, R. de A.; MACIEL, L. S. B. Fonte investigadora em educação: registros do banco de teses da CAPES. Educação e Pesquisa, São Paulo, v. 33, n. 2, p. 353-367, maio/ago. 2007. ZIEGLER, F. L. S. Letramentos acadêmicos de alunos de letras de uma universidade do sul do Brasil. 2015. Dissertação (Mestrado em Letras) - Centro de Artes e Letras, Universidade Federal de Santa Maria, Santa Maria, 2015. 